\title{
Effects of aliskiren- and ramipril-based treatment on central aortic blood pressure in elderly with systolic hypertension: a substudy of AGELESS
}

This article was published in the following Dove Press journal:

Vascular Health and Risk Management

25 June 2014

Number of times this article has been viewed

\section{Fabio Baschiera' \\ William Chang ${ }^{2}$ \\ Patrick Brunel'}

On behalf of the AGELESS

Study Group

'Novartis Pharma AG, Basel, Switzerland; ${ }^{2}$ Novartis

Pharmaceuticals Corporation,

East Hanover, NJ, USA
Correspondence: Patrick Brunel Cardiovascular and Metabolism Department, Novartis Campus, Fabrikstrasse 4-3.I4.4 CH-4056

Basel, Switzerland

$\mathrm{Tel}+4$ I 6 I 3240245

Fax +4I 6I 3242078

Email patrick.brunel@novartis.com
Background: Systolic hypertension is the most common form of hypertension in elderly patients. There is increasing evidence that measurement of central aortic pressure (CAP) better accounts for cardiovascular risk than brachial blood pressure (BP). The Aliskiren for GEriatric LowEring of SyStolic hypertension (AGELESS) study in elderly patients with systolic hypertension showed that aliskiren-based therapy provided greater reductions in peripheral BP than ramipril-based therapy over 12 and 36 weeks of treatment. Here, we present CAP results in a substudy of elderly patients from the AGELESS study.

Methods: This was a post hoc analysis of a 36-week, randomized, double-blind, parallelgroup, active-controlled, optional-titration study in patients $\geq 65$ years of age with systolic $\mathrm{BP} \geq 140 \mathrm{mmHg}$. Changes in both central and peripheral BP and pulse pressure (PP) and changes in systolic and PP amplification ratios from baseline to the week 36 end point with aliskiren-based versus ramipril-based therapy were analyzed.

Results: Of the 901 patients randomized in the overall study, 154 patients (aliskiren, $n=78$; ramipril, $n=76$ ) had CAP data. Numerically comparable reductions were seen for central aortic systolic pressure (CASP) in aliskiren-based therapy (baseline: 143.7 \pm 15.0 ; week 36: $-20.3 \pm 16.2$ ) compared with ramipril-based therapy (baseline: $147.9 \pm 11.9$; week 36 : $-20.7 \pm 14.6$ ). However, for the change in central aortic diastolic pressure, the least squares mean between-treatment difference $(-3.6 \mathrm{mmHg}$ [95\% confidence interval, $-6.76,-0.43 ; P=0.0263])$ was in favor of aliskiren, while the other changes were comparable between the two groups with a trend in favor of aliskiren for CASP as well $(-2.6 \mathrm{mmHg}$ [95\% confidence interval, $-7.38,2.19 ; P=0.2855)]$. Correlation coefficients for change from baseline between CASP and systolic BP and between central aortic pulse pressure and PP $(\mathrm{r}=0.8, P<0.0001)$ were highly significant.

Conclusion: Aliskiren-based therapy provides comparable reductions in CASP to ramipril-based therapy. Although the results did not reach statistical significance, these findings, when coupled with those of the main study, suggest that aliskiren may offer effective control of central BP in elderly patients with systolic hypertension and may be a good alternative to ramipril.

Keywords: aliskiren, central aortic pressure, elderly, ramipril, systolic hypertension

\section{Introduction}

Hypertension is the second most common disease in the elderly, and is rapidly increasing worldwide. ${ }^{1}$ Highly prevalent in the elderly population in the United States and Europe, the frequency of hypertension ranges between $53 \%$ and $72 \%$, and it is a major risk factor for heart disease, stroke, congestive heart failure, and kidney disease. ${ }^{2}$ Systolic hypertension (systolic BP [SBP] $>140 \mathrm{mmHg}$ ) is the most common form of hypertension in the elderly. ${ }^{3}$ Increased stiffness of the vessel walls of the major arteries is a major contributor to the rise in SBP seen in these patients. ${ }^{4}$ 
Consequently, the pulsatile components of central and peripheral pressures (SBP and pulse pressure [PP]) may vary significantly. ${ }^{5}$ There is a gradual shift in BP indices from diastolic BP (DBP) to SBP and then to PP as predictors of the risk of coronary heart disease with increasing age. DBP has been shown to be the strongest predictor in patients aged 50 years, and, from 60 years onwards, DBP was demonstrated to be negatively related to the risk of coronary heart disease making PP superior to SBP. ${ }^{6}$

In elderly patients and in patients with comorbid conditions, such as obesity and diabetes, measurement of brachial SBP can only provide a partial estimation of the real cardiovascular risk, whereas increasing evidence indicates that central aortic pressure (CAP) better accounts for the real arterial resistance and treatment effect at the root of the heart. ${ }^{7,8}$ The relationship between the central and the radial pressure waveform has been quantified with a transfer function that has allowed further insights into the long-term effects of hypertension on the hemodynamics of large vessels. There is growing evidence suggesting that an increase in central hemodynamic variables may be a stronger independent predictor of organ damage and cardiovascular risk than increase in peripheral BP. ${ }^{9-11}$

A systematic review and meta-analysis of pooled data from 5,648 subjects indicated that central hemodynamic indices are independent predictors of future cardiovascular events and all-cause mortality when compared with peripheral BP. ${ }^{12}$ Recently, it was also shown that the 24-hour circadian rhythms for central aortic systolic pressure (CASP) and central PP differ significantly from the circadian rhythms for brachial SBP and brachial PP, most notably at night, suggesting that nocturnal central aortic pressures could have previously unrecognized implications for pressure-mediated disease pathophysiology and strategies for the optimal evaluation and treatment of hypertension. ${ }^{13}$

Aliskiren, an oral direct renin inhibitor, has been shown to be effective in lowering CAP in combination with other antihypertensive drugs, resulting in significant improvement in vascular function. ${ }^{14-16}$ However, despite the evidence that small reductions in CAP are associated with improved outcomes, and that antihypertensive drugs may provide benefits beyond their reduction in peripheral BP, there are few prospective studies focusing on controlling CASP.

The Aliskiren for Geriatric Lowering of SyStolic hypertension (AGELESS) study in elderly patients with systolic hypertension showed that aliskiren-based therapy (with optional addition of hydrochlorothiazide [HCTZ] and amlodipine) provided greater reductions in peripheral BP than therapy based on ramipril (an angiotensin-converting enzyme [ACE] inhibitor) over 12 and 36 weeks of treatment. ${ }^{17}$ In this substudy, we report the effects of aliskiren and ramipril on SBP and CASP, measured as central mean pressure of systole in a subset of elderly patients ( $\geq 65$ years) with systolic hypertension.

\section{Methods}

\section{Study design}

AGELESS was a 36-week, randomized, double-blind, parallel-group, active-controlled, optional-titration study comparing the efficacy and safety of an aliskiren-based antihypertensive therapy with a ramipril-based therapy in 901 patients aged $\geq 65$ years with systolic hypertension. ${ }^{17}$ The study design and main results have been published elsewhere. ${ }^{17}$ A subgroup of this elderly population underwent, as per protocol, an assessment of CAP with the SphygmoCor device (AtCor Medical Pty Ltd, West Ryde, NSW, Australia) and the results were analyzed post hoc. Aliskiren 150-300 mg per day or ramipril 5-10 mg per day was administered for 12 weeks with optional add-on therapy of HCTZ (12.5-25 mg per day) at week 12 and amlodipine (5-10 $\mathrm{mg}$ per day) at any time after week 22 . The primary end point was non-inferiority of aliskiren versus ramipril monotherapy for change from baseline in mean sitting SBP at week $12 .{ }^{17}$

\section{Patients}

Men and women aged $\geq 65$ years with essential hypertension (mean sitting SBP $\geq 140 \mathrm{mmHg}$ and $<180 \mathrm{mmHg}$, and mean sitting DBP [msDBP] $<110 \mathrm{mmHg}$ ) were enrolled in the study. Detailed inclusion and exclusion criteria have been published previously. ${ }^{17}$ The key exclusion criteria were history of severe cardiovascular or cerebrovascular disease or other life threatening medical conditions, serum sodium or potassium less than the lower limit of normal, and severe renal impairment, defined as estimated glomerular filtration rate $<30 \mathrm{~mL} / \mathrm{min} / 1.73 \mathrm{~m}^{2}{ }^{18}$

The study was performed in compliance with the Guidelines for Good Clinical Practice and the Declaration of Helsinki Principles (2002) of the World Medical Association ${ }^{19}$ after receiving approval from the local and central institutional review boards/independent ethics committees/research ethics boards for each center. All patients provided written informed consent before the start of the study. This study is registered with ClinicalTrials.gov (NCT00368277).

\section{Study objectives}

This post hoc analysis evaluated the changes in SBP, CASP, and other CAP variables from baseline to the end 
of study (week 36) with aliskiren-based therapy versus ramipril-based therapy in a subset of patients randomly assigned at selected centers ( $n=154,78 / 76$ aliskiren/ ramipril). The primary end point of the main study was the noninferiority change in msSBP from baseline to the week 12 end point between aliskiren and ramipril. If aliskiren was shown to be noninferior to ramipril, superiority was tested. Secondary end points included the evaluation of the change from baseline in msSBP at the week 36 end point with aliskiren-based therapy versus ramipril-based therapy and the change from baseline in msDBP at the week 12 and 36 end points.

\section{Efficacy assessments}

In the current subanalyses, efficacy assessments included change in both CAP and peripheral BP, including PP and change in systolic (SBP/CASP) and PP amplification ratio (PP/central aortic pulse pressure [CAPP]) from baseline to the end of study (week 36 end point) with aliskiren-based therapy versus ramipril-based therapy. Correlation between changes in CASP versus SBP and CAPP versus PP from baseline to the week 36 end point was assessed.

Peripheral BP was measured using a standard mercury sphygmomanometer at trough ( $24 \pm 3$ hours postdose $)^{17}$ and was recorded at all study visits. BP measurements were taken three times at 2 minute intervals after resting for at least 5 minutes in the sitting position. The reported BP for the visit was the mean of all these readings.

CAP variables were measured at randomization and after 36 weeks of treatment. CAP was recorded by applanation tonometry of the radial artery using the SphygmoCor ${ }^{\circledR}$ device which is applied at the level of the wrist just after the measurement of peripheral BP, serving also as the calibration BP. The average ascending aortic (central) waveform was automatically synthesized from the radial pressure data by a validated, generalized transfer function, and aortic (central) systolic and diastolic pressure were calculated from the aortic waveform.

\section{Statistical analyses}

The intent-to-treat (ITT) population included all randomized patients who had a baseline assessment and at least one postbaseline assessment of an efficacy variable. The ITT CAP population included all patients in the ITT population with at least one CAP variable measurement. Following the ITT principle, patients were analyzed according to the treatment they were assigned at randomization. All statistical analyses were performed using SAS software version 9.1 or higher (SAS Institute, Inc., Cary, NC, USA).

In the substudy analysis, the changes from baseline in CASP and other CAP variables at the week 36 end point were analyzed using an analysis of covariance (ANCOVA) model with treatment, age strata, and region as factors, and the baseline value as the covariate. Pearson's partial correlation (adjusted for treatment) was also reported for the change from baseline to the week 36 end point between CASP versus SBP and CAPP versus PP.

The main study was analyzed as previously reported. ${ }^{17}$ The last observation carried forward was used to impute missing values in discontinued patients. The noninferiority margin was prespecified as $3.5 \mathrm{mmHg}$ in msSBP change, and if the noninferiority test was statistically significant, a supplementary superiority test was also performed. ANCOVA was performed with treatment regimen, age strata, and region as factors and baseline msSBP as the covariate.

\section{Results \\ Patient demographics}

Of the 901 patients randomized in the overall study, 154 patients with CAP data (aliskiren, $n=78$; ramipril, $n=76$ ) were included in this post hoc analysis. Patient demographics and baseline characteristics were comparable between treatment arms for patients in the CAP substudy (Table 1). The mean age of all patients was 72.3 years (standard deviation, 5.5), $51.9 \%$ were male, $90.9 \%$ were Caucasian, and $16.2 \%$ had diabetes. Patients aged $\geq 75$ years comprised $29.9 \%$ of the total population. The baseline msSBP and msDBP values for patients in the CAP subset were similar to those for the overall AGELESS full analysis set population. ${ }^{17}$ Almost all baseline characteristics were similar to those of the overall population.

\section{Efficacy}

In the main study, the aliskiren-based therapy showed a significantly greater reduction in SBP at week 12 (the primary efficacy variable). ${ }^{17}$ At the end of week 36 , the aliskirenbased therapy was proven to be statistically non-inferior but the superiority testing did not reach statistical significance, with a significantly higher rate of patients in the ramipril arm recurring to the addition of HCTZ and amlodipine with respect to the aliskiren arm (aliskiren versus ramipril: $46.3 \%$ versus $55.5 \% ; P=0.0048$ required HCTZ; and $11.5 \%$ versus $15.7 \% ; P=0.0481$ required add-on with both $\mathrm{HCTZ}$ and amlodipine). ${ }^{17} \mathrm{At}$ the week 36 end point, the least square mean (LSM) change (standard error [SE]) from baseline in 
Table I Patient demographics and baseline characteristics

\begin{tabular}{|c|c|c|c|c|}
\hline \multirow[t]{2}{*}{ Parameter } & \multicolumn{2}{|l|}{ CAP subset } & \multicolumn{2}{|c|}{ Overall population } \\
\hline & $\begin{array}{l}\text { Aliskiren-based } \\
\text { therapy } \\
(n=78)\end{array}$ & $\begin{array}{l}\text { Ramipril-based } \\
\text { therapy } \\
(n=76)\end{array}$ & $\begin{array}{l}\text { Aliskiren-based } \\
\text { therapy } \\
(n=457)\end{array}$ & $\begin{array}{l}\text { Ramipril-based } \\
\text { therapy } \\
(\mathrm{n}=444)\end{array}$ \\
\hline Age, years & $72.6 \pm 5.4$ & $72.0 \pm 5.6$ & $72.0 \pm 5.6$ & $72.2 \pm 5.6$ \\
\hline$\geq 65-<75$ years, $n(\%)$ & $55(70.5)$ & $53(69.7)$ & $312(68.3)$ & $296(66.7)$ \\
\hline$\geq 75$ years, $n(\%)$ & $23(29.5)$ & $23(30.3)$ & $145(3 \mid .7)$ & $148(33.3)$ \\
\hline \multicolumn{5}{|l|}{ Race, n (\%) } \\
\hline Caucasian & $70(89.7)$ & $70(92.1)$ & $389(85.1)$ & $378(85.1)$ \\
\hline Males, n (\%) & $44(56.4)$ & $36(47.4)$ & $222(48.6)$ & $207(46.6)$ \\
\hline Nonsmoker, n (\%) & $73(93.6)$ & 71 (93.4) & $415(90.8)$ & $398(89.6)$ \\
\hline Heart rate (bpm) & 66.7 & 66.8 & $70.1 \pm 9.7$ & $70.6 \pm 10.6$ \\
\hline $\mathrm{BMI}, \mathrm{kg} / \mathrm{m}^{2}$ & $29.3 \pm 4.7$ & $29.5 \pm 6.2$ & $29.6 \pm 5.7$ & $29.4 \pm 5.7$ \\
\hline Duration of hypertension, years & $|3.1 \pm| \mid .8$ & $12.9 \pm 11.4^{b}$ & $12.0 \pm 10.8$ & $11.3 \pm 10.2$ \\
\hline eGFR $\left(\mathrm{mL} / \mathrm{min} / \mathrm{I} .73 \mathrm{~m}^{2}\right)$ & $79.9 \pm 20.8^{\mathrm{a}}$ & $78.2 \pm 18.8^{b}$ & $78.4 \pm 19.1$ & $78.4 \pm 19.0$ \\
\hline \multicolumn{5}{|l|}{ eGFR group, n (\%) } \\
\hline$\geq 30-<60 \mathrm{~mL} / \mathrm{min} / 1.73 \mathrm{~m}^{2}$ & II (I4.I) & $13(17.1)$ & $79(17.3)$ & $78(17.6)$ \\
\hline$\geq 60 \mathrm{~mL} / \mathrm{min} / \mathrm{I} .73 \mathrm{~m}^{2}$ & $66(84.6)$ & $62(81.6)$ & $363(81.8)$ & $737(81.8)$ \\
\hline Diabetes, $\mathrm{n}(\%)$ & 14 (I7.9) & II (I4.5) & $99(21.7)$ & $87(19.6)$ \\
\hline $\mathrm{SBP}, \mathrm{mmHg}$ & $155.2 \pm 12.0$ & $157.5 \pm 10.9$ & $156.5 \pm 10.9$ & $156.6 \pm 10.6$ \\
\hline $\mathrm{DBP}, \mathrm{mmHg}$ & $83.4 \pm 10.3$ & $86.4 \pm 9.2$ & $85.5 \pm 9.5$ & $86.0 \pm 9.0$ \\
\hline $\mathrm{PP}, \mathrm{mmHg}$ & $71.9 \pm 12.5$ & $7 I .1 \pm 12.7$ & - & - \\
\hline $\mathrm{CASP}^{\mathrm{b}}, \mathrm{mmHg}$ & $143.7 \pm 15.0$ & $147.9 \pm 11.9$ & & - \\
\hline $\mathrm{CADP}^{\mathrm{b}}, \mathrm{mmHg}$ & $83.0 \pm 9.9$ & $87.3 \pm 9.3$ & - & - \\
\hline CAPPb, mmHg & $60.6 \pm 12.8$ & $60.6 \pm 13.1$ & - & - \\
\hline Systolic amplification ratio (SBP/CASP) ${ }^{\mathrm{b}}$ & $1.09 \pm 0.10$ & $\mathrm{I} .07 \pm 0.04$ & - & - \\
\hline Pulse pressure amplification ratio (PP/CAPP) ${ }^{\mathrm{b}}$ & $1.22 \pm 0.22$ & $1.18 \pm 0.12$ & - & - \\
\hline
\end{tabular}

Notes: Data are shown as mean \pm standard deviation unless otherwise stated. ${ }^{a} \mathrm{n}=77 ;{ }^{\mathrm{b}} \mathrm{n}=75$.

Abbreviations: BMI, body mass index; bpm, beats per minute; CAP, central aortic pressure; CASP, central aortic systolic pressure; DBP, diastolic blood pressure; eGFR, estimated glomerular filtration rate; SBP, systolic blood pressure; PP, pulse pressure ; CAPP, central aortic pulse pressure; CADP, central aortic diastolic pressure.

msSBP was -20.0 (0.79) and -18.1 (0.79) for aliskiren-based therapy and ramipril-based therapy, respectively. For msDBP, the LSM change (SE) from baseline was $-8.2(0.41)$ and -7.0 (0.41) for aliskiren-based therapy and ramipril-based therapy, respectively.

In this current subset analysis, aliskiren-based therapy provided numerically greater reductions from baseline to the week 36 end point in SBP than ramipril-based therapy, from $155.2 \pm 12.0$ to $134.3 \pm 18.5 \mathrm{mmHg}$ (mean change $-20.9 \pm 16.9 \mathrm{mmHg}$ ) and from $157.5 \pm 10.9$ to 137.6 $\pm 14.6 \mathrm{mmHg}$ (mean change $-19.9 \pm 14.2 \mathrm{mmHg}$ ), respectively (Figure 1). Similarly, numerically greater reductions from baseline to the week 36 end point were observed in DBP with aliskiren-based therapy. For CASP, numerically comparable reductions were observed with aliskiren-based therapy compared to ramipril-based therapy, with a trend in favor of aliskiren (LSM treatment difference, $-2.6 \mathrm{mmHg}$ [95\% confidence interval [CI], -7.38, 2.19; $P=0.2855]$; Table 3). Numerically greater reductions that were statistically significant were obtained for central aortic diastolic pressure (CADP) (Table 2) with aliskiren-compared to ramipril-based therapy with a LSM treatment difference of $-3.6 \mathrm{mmHg}(95 \% \mathrm{CI},-6.76,-0.43$; $P=0.0263$; Table 3 ). Changes in other parameters were comparable between the two groups.

The reduction obtained in both PP and CAPP was similar to those of the relative amplification ratios (Table 2). Estimated Pearson's correlation coefficients indicate significant correlations between the two methods of BP assessments. Correlation coefficients for change from baseline between CASP and SBP $(r=0.8, P<0.0001)$ (Figure 2) and between CAPP and PP $(r=0.8, P<0.0001$; Figure 3) were highly significant.

\section{Safety}

Overall, the severity and incidence of adverse events were similar for the two treatment regimens, except for cough. Significantly fewer patients reported cough with aliskiren-based therapy $(4.2 \%)$ than ramiprilbased therapy $(13.3 \%)(P<0.001)$. Detailed safety and tolerability findings from the study have been published elsewhere. ${ }^{17}$ 


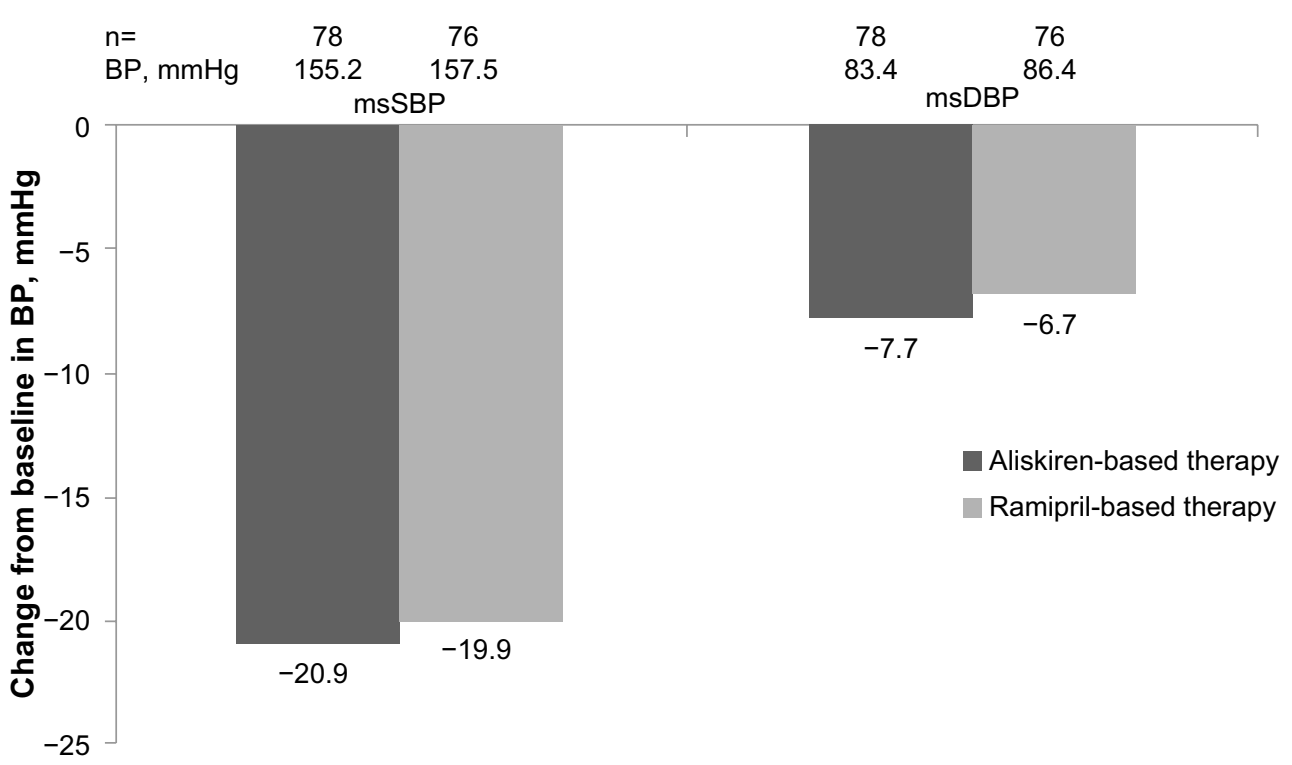

Figure I The effect of aliskiren-based and ramipril-based therapy on peripheral blood pressure at the week 36 end point.

Abbreviations: BP, blood pressure; msDBP, mean sitting diastolic blood pressure; msSBP, mean sitting systolic blood pressure.

\section{Discussion}

Age-related structural and functional changes in the aorta are predominantly associated with increased stiffness, resulting in measurable secondary changes in central and peripheral pressure wave morphology. There is growing evidence suggesting that central hemodynamic variables are independently associated with target organ damage, and potentially with cardiovascular risk. ${ }^{10,20}$ In addition, the PP amplification ratio may provide complementary data to BP regarding the management of arterial hypertension. ${ }^{5}$ Furthermore, the 5-year follow-up data from the Strong Heart Study showed that the noninvasively determined central PP predicts incident cardiovascular disease better than the corresponding brachial $\mathrm{PP}$ and peripheral $\mathrm{PP}^{21}$
In the overall population of the main study, at 36 weeks aliskiren-based therapy was noninferior to ramipril-based therapy for lowering SBP $(-20.0 \mathrm{mmHg}$ versus $-18.1 \mathrm{mmHg}$; $P=0.07$ ), and lowering of DBP was significantly superior with aliskiren-based therapy to that observed with ramiprilbased therapy $(-8.2 \mathrm{mmHg}$ versus $-7.0 \mathrm{mmHg} ; P=0.03)$. The results of the present analysis showed that aliskiren-based therapy provides numerically greater reductions in CASP than ramipril-based therapy. Although the data did not reach statistical significance, most likely because of the limited sample size, these findings coupled with those of the main study suggest that aliskiren may offer effective control of central BP in elderly patients with systolic hypertension, which may in turn offer further cardiovascular protection. Similar

Table 2 Change in mean peripheral and central variables from baseline to the week 36 end point

\begin{tabular}{|c|c|c|c|c|c|c|}
\hline \multirow[t]{2}{*}{ Parameter, mmHg } & \multicolumn{3}{|c|}{ Aliskiren-based therapy $(n=78)$} & \multicolumn{3}{|c|}{ Ramipril-based therapy $(n=76)$} \\
\hline & Baseline & Week 36 & $\begin{array}{l}\text { Change from } \\
\text { baseline }\end{array}$ & Baseline & Week 36 & $\begin{array}{l}\text { Change from } \\
\text { baseline }\end{array}$ \\
\hline SBP & $155.2 \pm 12.0$ & $134.3 \pm 18.5$ & $-20.9 \pm 16.9$ & $157.5 \pm 10.9$ & $137.6 \pm 14.6$ & $-19.9 \pm 14.2$ \\
\hline DBP & $83.4 \pm 10.3$ & $75.7 \pm 10.8$ & $-7.7 \pm 9.3$ & $86.4 \pm 9.2$ & $79.6 \pm 10.4$ & $-6.7 \pm 9.9$ \\
\hline PP & $\begin{array}{l}71.9 \pm 12.5 \\
(n=59)\end{array}$ & $58.6 \pm 15.3$ & $-13.3 \pm 13.4$ & $\begin{array}{l}71.1 \pm 12.7 \\
(n=66)\end{array}$ & $58.0 \pm 13.4$ & $-13.1 \pm 12.8$ \\
\hline CASP & $143.8 \pm 13.9$ & $123.5 \pm 14.9$ & $-20.3 \pm 16.2$ & $147.8 \pm 12.1$ & $127.1 \pm 12.8$ & $-20.7 \pm 14.6$ \\
\hline CADP & $83.4 \pm 10.1$ & $75.0 \pm 10.4$ & $-8.4 \pm 9.6$ & $87.6 \pm 9.2$ & $8 I .1 \pm 10.4$ & $-6.4 \pm 9.6$ \\
\hline CAPP & $60.5 \pm 12.1$ & $48.5 \pm 12.7$ & $-12.0 \pm 12.1$ & $60.2 \pm 13.1$ & $46.0 \pm 11.8$ & $-14.2 \pm 13.7$ \\
\hline Systolic amplification ratio (SBP/CASP) $)^{\ddagger}$ & $1.08 \pm 0.07$ & $1.07 \pm 0.05$ & $-0.0 \mathrm{I} \pm 0.07$ & $1.07 \pm 0.04$ & $1.09 \pm 0.09$ & $0.02 \pm 0.09$ \\
\hline Pulse pressure amplification ratio (PP/CAPP) $)^{\ddagger}$ & $1.20 \pm 0.15$ & $1.21 \pm 0.14$ & $0.01 \pm 0.17$ & $1.19 \pm 0.13$ & $1.28 \pm 0.33$ & $0.08 \pm 0.33$ \\
\hline
\end{tabular}

Notes: Data are shown as mean \pm standard deviation; ${ }^{\ddagger}$ no units.

Abbreviations: CADP, central aortic diastolic pressure; CAPP, central aortic pulse pressure; CASP, central aortic systolic pressure; DBP, diastolic blood pressure; SBP, systolic blood pressure; PP, pulse pressure. 
Table 3 Between treatment analysis results for the changes from baseline at the week 36 end point (ITT CAP population)

\begin{tabular}{|c|c|c|c|c|c|}
\hline \multirow{2}{*}{$\begin{array}{l}\text { Parameter, } \\
\mathrm{mmHg}\end{array}$} & \multicolumn{2}{|c|}{ Pairwise comparison LSM (SE) } & \multirow[t]{2}{*}{ LSM (SE) } & \multirow[t]{2}{*}{$95 \% \mathrm{Cl}$} & \multirow[t]{2}{*}{$P$-value } \\
\hline & $\begin{array}{l}\text { Aliskiren-based } \\
\text { therapy }(n=78)\end{array}$ & $\begin{array}{l}\text { Ramipril-based } \\
\text { therapy }(n=76)\end{array}$ & & & \\
\hline SBP & $-22.9(2.09)$ & $-20.6(2.10)$ & $-2.3(2.47)$ & $-7.18,2.59$ & 0.3556 \\
\hline DBP & $-9.0(1.2 \mathrm{I})$ & $-7.1(1.23)$ & $-1.9(1.44)$ & $-4.73,0.95$ & 0.1900 \\
\hline PP & $-14.0(1.64)$ & $-13.5(1.65)$ & $-0.5(1.94)$ & $-4.34,3.31$ & 0.7907 \\
\hline CASP & $-20.9(2.19)^{\mathrm{a}}$ & $-18.3(2.19)^{b}$ & $-2.6(2.42)$ & $-7.38,2.19$ & 0.2855 \\
\hline CADP & $-9.3(1.43)^{\mathrm{a}}$ & $-5.7(1.44)^{b}$ & $-3.6(1.60)$ & $-6.76,-0.43$ & 0.0263 \\
\hline CAPP & $-I I . I(I .74)^{\mathrm{a}}$ & $-12.8(1.76)^{b}$ & $1.7(1.93)$ & $-2.16,5.48$ & 0.3908 \\
\hline
\end{tabular}

Notes: ${ }^{\mathrm{a}} \mathrm{n}=59 ;{ }^{\mathrm{b}} \mathrm{n}=66$.

Abbreviations: ITT CAP, intent-to-treat central aortic pressure; CADP, central aortic diastolic pressure; CAPP, central aortic pulse pressure; CASP, central aortic systolic pressure; $\mathrm{Cl}$, confidence interval; DBP, diastolic blood pressure; LSM, least square means; PP, pulse pressure; SBP, systolic blood pressure; SE, standard error.

results were obtained in the ASSERTIVE (AliSkiren Study of profound antihypERtensive efficacy inhyperTensIVE patients) study, in which aliskiren monotherapy was compared with the angiotensin II receptor antagonist telmisartan, with significant CASP lowering potential more evident and sustained after treatment interruption. ${ }^{22}$ The differences in the central effects of the drugs may be attributable to their predominant mechanism of action and the vascular substrate of aging patients. In a recent population-based study by Bia et al in Latin American patients, stable arterial diameter dilatation was observed with increasing age, particularly above 60 years when degeneration of elastic fibers and intima media is more prominent. ${ }^{23}$ It is also important to mention that the differential effect of various antihypertensive agents (ACE inhibitors, calcium channel blockers, and diuretics) based on brachial artery recordings and their effect on central aortic SBP may be over- or underestimated..$^{24,25}$
As seen in the present study, previous studies with aliskiren have shown clinically relevant BP reduction in office BP, ambulatory BP, and central BP. ${ }^{26-29}$ A 12 -week study that directly compared the effects of aliskiren with ramipril on central hemodynamics in hypertensive patients showed that brachial BP was similarly normalized by aliskiren (from 149/94 $\mathrm{mmHg}$ to $136 / 86 \mathrm{mmHg}$ ) and ramipril (from 148/92 $\mathrm{mmHg}$ to $135 / 85 \mathrm{mmHg}$ ), as well as central SBP (from $137 \mathrm{mmHg}$ to $123 \mathrm{mmHg}$ and from $134 \mathrm{mmHg}$ to $122 \mathrm{mmHg}$, respectively). ${ }^{30} \mathrm{An} 8$-week study in patients with stage 2 hypertension showed significant reductions in both central SBP and central DBP from baseline, consistent with the clinical BP measures and in favor of aliskiren/HCTZ compared to ramipril. ${ }^{31}$ In the present study, a close relationship between the changes in peripheral BP and CASP, as well as for PP and CAPP, was observed for both aliskiren and ramipril. Minor differences

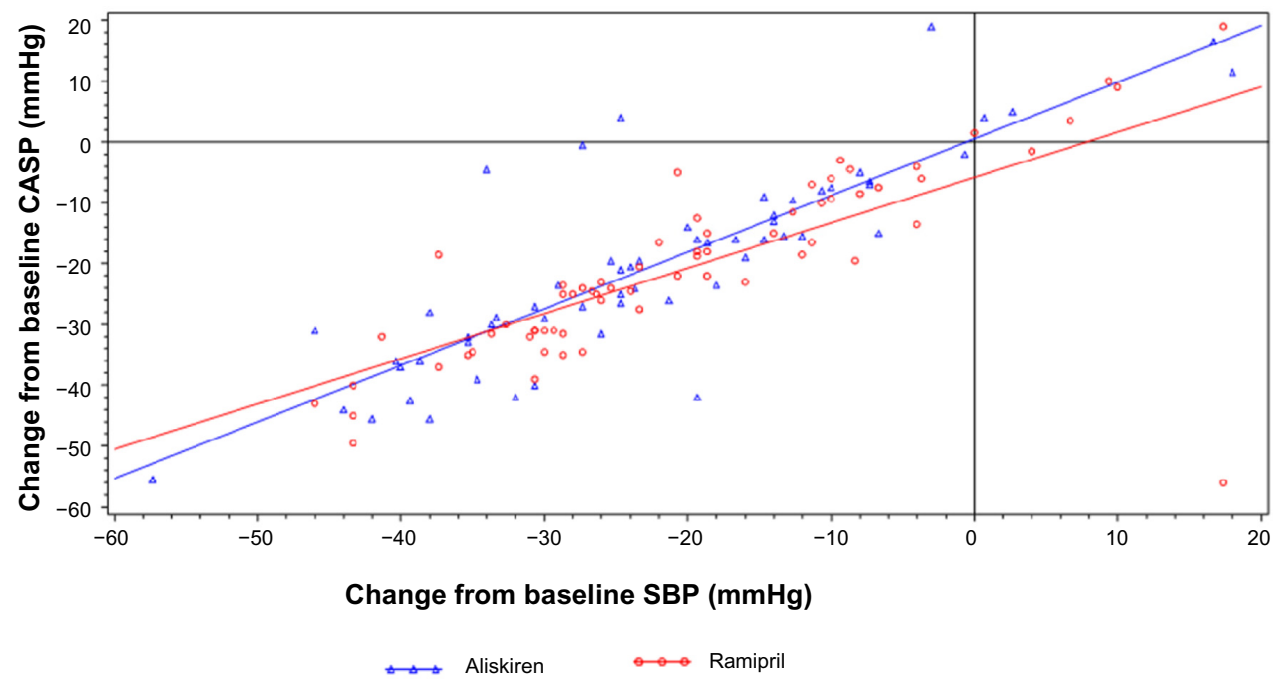

Figure 2 Relationship between the changes in central aortic systolic pressure $(\mathrm{mmHg})$ and changes in systolic blood pressure (mmHg) from baseline to the week 36 end point by treatment.

Abbreviations: CASP, central aortic systolic pressure; SBP, systolic blood pressure. 


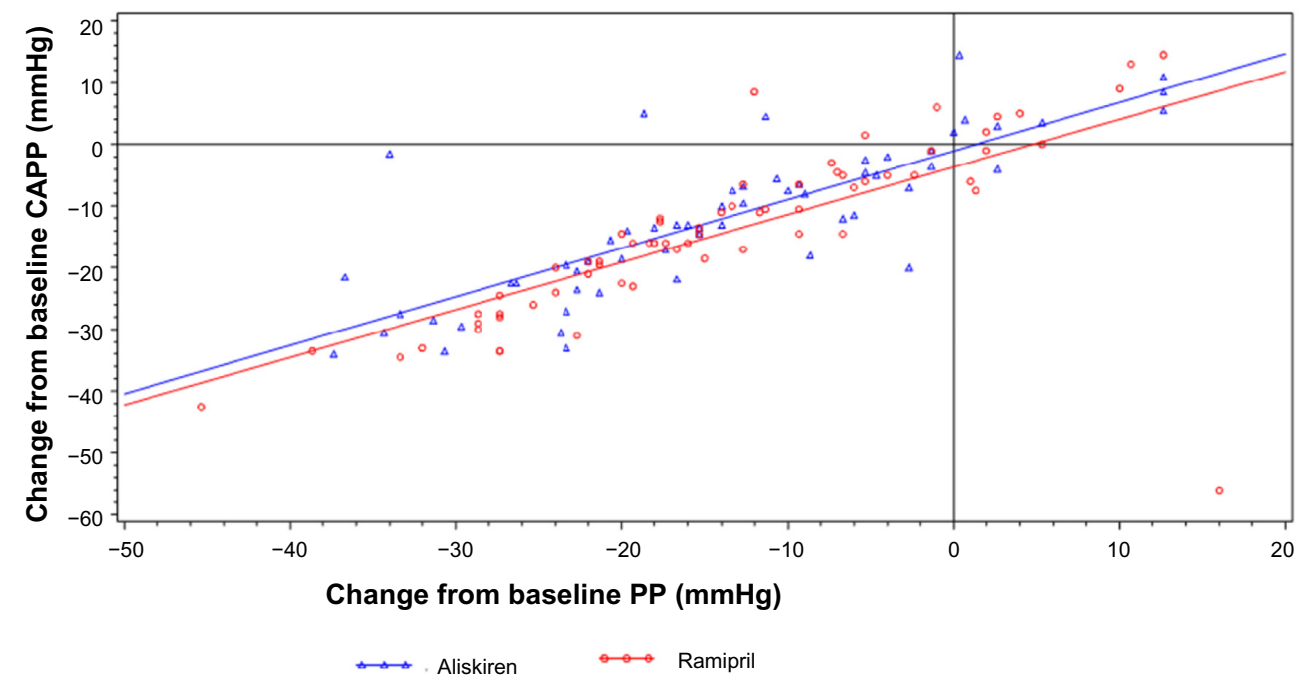

Figure 3 Relationship between the changes in central aortic pulse pressure $(\mathrm{mmHg})$ and changes in pulse pressure ( $\mathrm{mmHg}$ ) from baseline to the week 36 end point by treatment.

Abbreviations: CAPP, central aortic pulse pressure; PP, pulse pressure.

for CASP versus SBP between aliskiren and ramipril were not seen to be clinically relevant. The significant correlation between peripheral and central BPs observed in this study is in accordance with a previous study in which the estimated Spearman correlation coefficients between central BPs $(r=0.68 ; P<0.0001)$ were highly significant. ${ }^{31}$ The purpose of showing the correlation is to look at the treatment effects on the relationship (slope) since each treatment may affect the amplification ratio between the peripheral and central blood pressures differently. Results are not surprising in this study since we are comparing two blockers of the reninangiotensin-aldosterone system (RAAS); it was different in other cases with different mechanisms of action, eg, beta-blockers and calcium blockers like in ASCOT-CAFE (Anglo-Scandinavian Cardiac Outcomes Trial-Conduit Artery Function Evaluation). ${ }^{32}$

Studies that consider the effects of antihypertensive therapies on central and brachial pressures may have increasing influence on the choice of drugs in elderly patients. In this regard, collective data have shown that RAAS inhibitors decrease aortic SBP at least as much as brachial SBP. Diuretics lower both central and brachial systolic pressures commensurately. However, beta-blockers increase the augmentation index and do not lower central SBP and PP to the same degree as brachial pressure. ${ }^{33}$

Two 8-week studies conducted in African American patients with hypertension have shown that the aliskiren/amlodipine combination reduced the central SBP/DBP and central mean pressures to a greater extent than amlodipine with no differences in central PP and PP amplification ratio. ${ }^{14,34}$
Another study showed that aliskiren/HCTZ significantly reduced central SBP and increased the PP amplification ratio to a greater extent than amlodipine. ${ }^{15}$ The increasing sets of data are paving the way for the use of central aortic BP in the management of hypertension, and the correspondence of values obtained within each group between peripheral BP and CASP measurements supports this innovative concept. A recent study used central aortic $\mathrm{BP}$ as a guide for treatment versus 24-hour ambulatory measurement leading to a different intervention schedule and associated health care costs. ${ }^{35} \mathrm{In}$ addition, a systematic review and meta-analysis comparing the effects of different antihypertensive agents and their combinations showed reduction in both brachial and central BP with beta-blockers and diuretics reducing the central to brachial amplification. ${ }^{36}$

Limitations of the study were the small number of patients included and the fact that the results cannot be generalized. Additionally, the unbalanced presence of the add-on treatment, more frequent in the ramipril arm due to lower BP control, is likely to partially compensate both the $\mathrm{BP}$ and the CASP differences between the two arms, and the central BP data was not collected at 12 weeks.

In conclusion, these data indicate that aliskiren reduced brachial and central BP to a comparable extent to ramipril in elderly patients with systolic hypertension. These data further support the use of central pressure in the clinical setting, and show a strong correlation between clinical and central pressures. The results of this study suggest that aliskiren is an option for the treatment of systolic hypertension in elderly patients. 


\section{Acknowledgments}

This study was funded by Novartis Pharma AG, Basel, Switzerland. The authors acknowledge Dr Madhavi Dokku $(\mathrm{PhD})$ Novartis, Hyderabad, India, for writing assistance and editorial support in the development of the manuscript. We also thank AtCor Medical Pty Ltd for technical assistance and advises on the use of the SphygmoCor device.

The authors would also like to acknowledge the AGELESS Study Group: Evan Klass (New York, NY, USA); Collin Teguh (San Diego, CA, USA); Daniel Duprez (Minneapolis, MN, USA); Jackson Rhudy (Salt Lake City, UT, USA); Mark Munger (Salt Lake City, UT, USA); Steven Chrysant (Oklahoma City, OK, USA); Lanway Ling (Pensacola, FL, USA); Charles Knight (Pensacola, FL, USA); David Calhoun (Birmingham, AL, USA); Keith Klatt (Portland, OR, USA); Athol Morgan (Baltimore, MD, USA); Christopher Foley (Minneapolis, MN, USA); Michael Cromer (Tampa, FL, USA); Stephen Braden (Bryan, TX, USA); John Sensenbrenner (Charlotte, NC, USA); and Hugh Durrence (Charleston, SC, USA).

\section{Disclosure}

FB, WC and PB are Novartis employees therefore they are entitled to receive Novartis shares and stock options.

\section{References}

1. Vidt DG, Basile JN. Hypertension curriculum review. The importance of systolic blood pressure elevation in elderly persons. J Clin Hypertens (Greenwich). 2004;6(8):461-465.

2. Babatsikou F, Zavitsanou A. Epidemiology of hypertension in the elderly. Health Sci J. 2010;4(1):24-30.

3. Duprez DA. Systolic hypertension in the elderly: addressing an unmet need. Am J Med. 2008;121(3):179-184.

4. Tsiachris D, Tsioufis C, Dimitriadis K, et al. Relationship of ambulatory arterial stiffness index with blood pressure response to exercise in the early stages of hypertension. Blood Press Monit. 2010;15(3): $132-138$.

5. Agabiti-Rosei E, Mancia G, O’Rourke MF, et al. Central blood pressure measurements and antihypertensive therapy: a consensus document. Hypertension. 2007;50(1):154-160.

6. Franklin SS, Larson MG, Khan SA, et al. Does the relation of blood pressure to coronary heart disease risk change with aging? The Framingham Heart Study. Circulation. 2001;103(9): 1245-1249.

7. Avolio A. Central aortic blood pressure and management of hypertension: confirmation of a paradigm shift? Hypertension. 2013; 62(6):1005-1007.

8. Williams B, Lacy PS; CAFE and ASCOT (Anglo-Scandinavian Cardiac Outcomes Trial) Investigators. Impact of heart rate on central aortic pressures and hemodynamics: analysis from the CAFE (Conduit Artery Function Evaluation) study: CAFE-Heart Rate. J Am Coll Cardiol. 2009;54(8):705-713.

9. Jankowski P, Kawecka-Jaszcz K, Czarnecka D, et al; Aortic Blood Pressure and Survival Group. Pulsatile but not steady component of blood pressure predicts cardiovascular events in coronary patients. Hypertension. 2008;51(4):848-855.
10. Roman MJ, Devereux RB, Kizer JR, et al. Central pressure more strongly relates to vascular disease and outcome than does brachial pressure: the Strong Heart Study. Hypertension. 2007;50(1):197-203.

11. Roman MJ, Okin PM, Kizer JR, Lee ET, Howard BV, Devereux RB. Relations of central and brachial blood pressure to left ventricular hypertrophy and geometry: the Strong Heart Study. J Hypertens. 2010;28(2): 384-388.

12. Vlachopoulos C, Aznaouridis K, O’Rourke MF, Safar ME, Baou K, Stefanadis C. Prediction of cardiovascular events and all-cause mortality with central haemodynamics: a systematic review and meta-analysis. Eur Heart J. 2010;31(15):1865-1871.

13. Williams B, Lacy PS, Baschiera F, Brunel P, Dusing R. Novel description of the 24-hour circadian rhythms of brachial versus central aortic blood pressure and the impact of blood pressure treatment in a randomized controlled clinical trial: The Ambulatory Central Aortic Pressure (AmCAP) Study. Hypertension. 2013;61(6):1168-1176.

14. Izzo J, Weinberger M, Israel M, Hilkert R, Purkayastha D, Lee J, Black H. Aliskiren + amlodipine combination reduces central blood pressure more than amlodipine alone in African Americans with stage 2 hypertension: PP.5.171. J Hypertens. 2010;28:e99.

15. Ferdinand KC, Pool J, Weitzman R, Purkayastha D, Townsend R. Peripheral and central blood pressure responses of combination aliskiren/hydrochlorothiazide and amlodipine monotherapy in African American patients with stage 2 hypertension: the ATLAAST trial. J Clin Hypertens. 2011;13(5):366-375.

16. Kanaoka T, Tamura K, Ohsawa M, et al. Effects of aliskiren-based therapy on ambulatory blood pressure profile, central hemodynamics, and arterial stiffness in nondiabetic mild to moderate hypertensive patients. J Clin Hypertens (Greenwich). 2012;14(8):522-529.

17. Duprez DA, Munger MA, Botha J, Keefe DL, Charney AN. Aliskiren for geriatric lowering of systolic hypertension: a randomized controlled trial. J Hum Hypertens. 2010;24(9):600-608.

18. National Kidney Foundation. K/DOQI clinical practice guidelines for chronic kidney disease: evaluation, classification, and stratification. $\mathrm{Am}$ J Kidney Dis. 2002;39(2 Suppl 1):S1-S266.

19. European Medicines Agency. ICH E6 (R1) Guideline for Good Clinical Practice. London: European Medicines Agency; 2002. Available from: http://www.ema.europa.eu/docs/en_GB/document_library/Scientific_guideline/2009/09/WC500002874.pdf. Accessed June 12, 2014.

20. Ishisone T, Koeda Y, Tanaka F, Sato K, Nagano M, Nakamura M. Comparison of utility of arterial stiffness parameters for predicting cardiovascular events in the general population. Int Heart J. 2013;54(3): 160-165.

21. Palmieri V, Devereux RB, Hollywood J, et al. Association of pulse pressure with cardiovascular outcome is independent of left ventricular hypertrophy and systolic dysfunction: the Strong Heart Study. Am J Hypertens. 2006;19(6):601-607.

22. Dusing R, Brunel P, Baek I, Baschiera F. Sustained decrease in blood pressure following missed doses of aliskiren or telmisartan: the ASSERTIVE double-blind, randomized study. J Hypertens. 2012;30(5): 1029-1040.

23. Bia D, Zocalo Y, Farro I, et al. Integrated evaluation of age-related changes in structural and functional vascular parameters used to assess arterial aging, subclinical atherosclerosis, and cardiovascular risk in Uruguayan adults: CUiiDARTE Project. Int J Hypertens. 2011;2011:587303.

24. Mackenzie IS, McEniery CM, Dhakam Z, Brown MJ, Cockcroft JR, Wilkinson IB. Comparison of the effects of antihypertensive agents on central blood pressure and arterial stiffness in isolated systolic hypertension. Hypertension. 2009;54(2):409-413.

25. Morgan T, Lauri J, Bertram D, Anderson A. Effect of different antihypertensive drug classes on central aortic pressure. Am J Hypertens. 2004;17(2):118-123.

26. Black HR, Kribben A, Palacios FA, Bijarnia M, LaFlammeAK, Baschiera F. Aliskiren alone or in Combination with hydrochlorothiazide in patients with the lower ranges of stage 2 hypertension to provide QUick Intensive control of blood pressuRE: the ACQUIRE randomized, double blind study. J Clin Hypertension. 2010;12(12):917-926. 
27. Palatini P, Jung W, Shlyakhto E, Botha J, Bush C, Keefe DL. Maintenance of blood-pressure-lowering effect following a missed dose of aliskiren, irbesartan or ramipril: results of a randomized, double-blind study. Journal of Human Hypertension. 2010;24:93-103.

28. Düsing R, Brunel P, Baek IY, Baschiera F. Sustained blood pressure lowering effect of aliskiren compared with telmisartan after a single missed-dose. J Clin Hypertens. 2013;15(1):41-47.

29. Bonadei I, Vizzardi E, D’Aloia A, Sciatti E, Raddino R, Metra M. Role of aliskiren on arterial stiffness and endothelial function in patients with primary hypertension. J Clin Hypertens (Greenwich). 2014;16(3):202-206.

30. Virdis A, Ghiadoni L, Qasem AA, et al. Effect of aliskiren treatment on endothelium-dependent vasodilation and aortic stiffness in essential hypertensive patients. Eur Heart J. 2012;33(12):1530-1538.

31. Whaley-Connell A, Purkayastha D, Yadao A, Sowers JR. Central pressure and biomarker responses to renin inhibition with hydrochlorothiazide and ramipril in obese hypertensives: the ATTAIN study. Cardiorenal Med. 2011;1(1):53-66.

32. Williams B, Lacy PS, Thom SM, et al. Differential impact of blood pressure-lowering drugs on central aortic pressure and clinical outcomes: principal results of the Conduit Artery Function Evaluation (CAFE) study. Circulation. 2006;113(9):1213-1225.
33. Jankowski P, Safar ME, Benetos A. Pleiotropic effects of drugs inhibiting the renin-angiotensin-aldosterone system. Curr Pharm Des. 2009;15(5):571-584.

34. Black HR, Weinberger MH, Purkayastha D, et al. Comparative efficacy and safety of combination aliskiren/amlodipine and amlodipine monotherapy in African Americans with stage 2 hypertension. J Clin Hypertens (Greenwich). 2011;13(8):571-581.

35. Sharman JE, Marwick TH, Gilroy D, et al; Value of Central Blood Pressure for GUIDing ManagEment of Hypertension Study Investigators. Randomized trial of guiding hypertension management using central aortic blood pressure compared with best-practice care: principal findings of the BP GUIDE study. Hypertension. 2013;62(6): 1138-1145.

36. Manisty $\mathrm{CH}$, Hughes AD. Meta-analysis of the comparative effects of different classes of antihypertensive agents on brachial and central systolic blood pressure, and augmentation index. Br J Clin Pharmacol. 2013;75(1):79-92.
Vascular Health and Risk Management

\section{Publish your work in this journal}

Vascular Health and Risk Management is an international, peerreviewed journal of therapeutics and risk management, focusing on concise rapid reporting of clinical studies on the processes involved in the maintenance of vascular health; the monitoring, prevention and treatment of vascular disease and its sequelae; and the involvement of

\section{Dovepress}

metabolic disorders, particularly diabetes. This journal is indexed on PubMed Central and MedLine. The manuscript management system is completely online and includes a very quick and fair peer-review system, which is all easy to use. Visit http://www.dovepress.com/ testimonials.php to read real quotes from published authors. 